\title{
O OLHAR ATRAVÉS DE OUTRA LENTE
}

Passada essa fase expositiva, pudemos conhecer algumas das razões pelas quais o noticiário se tornou um show de horrores na atualidade. Era uma parte tão necessária quanto penosa, da qual não poderíamos escapar. Millôr Fernandes tem razão ao dizer que o Brasil tem como futuro o seu imenso passado. Superá-lo é um dos maiores desafios dessa e das próximas geraçóes e cada passo desse processo é um Everest a ser vencido.

Todavia, agora que o paciente já está minimamente diagnosticado, a elaboração da receita torna-se mais fácil, ou menos complexa. Serão ministrados antibióticos? Anti-inflamatórios? Em qual proporção? Com que frequência? Antes ou depois da alimentação? Para tratar dessa doença crônica que é a corrupção, a questão a respeito dos métodos e momentos é extremamente importante.

Somos um país onde a corrupção, a malversação de dinheiro público, é identificada apenas quando alcança milhões - ou bilhōes - de reais e porque um parente, sócio, ou delator, pretendendo benefícios futuros, decidiu colocar as cartas na mesa, e não por um processo eficiente e planejado de controle e auditoria interna ou externa. Quer dizer: no Brasil, o controle se acostumou a chegar depois, e funcionar basicamente como uma pá carregadeira, que sai recolhendo os destroços e procurando os responsáveis pela destruição do patrimônio econômico do Estado.

O déficit de confiança da população na capacidade do Estado de prover bens e serviços públicos de qualidade, além da descrença quanto ao funcionamento dos mecanismos de controle institucional, fortaleceram o impulso legislativo-compulsivo, através de fabricação de normas legais, a fim de conter o incêndio iminente. 
A excessiva e errática produção de normas punitivas resultou da concepção, tão simplista quanto equivocada, de que incrementar leis endurecendo o regime de responsabilidade é suficiente para que elas sejam cumpridas. Pode ser uma condição necessária para incutir nos infratores a percepção de que haverá consequências jurídicas para seus atos, mas certamente não é suficiente.

O assim denominado Sistema brasileiro de combate à corrupção põe à luz essa tendência a partir de um punhado de leis sancionatórias: Lei n. 8.429/92 (Lei de Improbidade Administrativa); Decreto-lei n. 2.848/40 (Código Penal); as leis que definem os crimes de responsabilidade (Lei n. 1.079/50, para Presidente da República, ministros de estado e governadores e Decreto-lei n. 201/67, aplicável a prefeitos e vereadores); Lei Complementar n. 135/2010 (Lei da Ficha Limpa), que alterou a Lei Complementar n. 64/90, estabelecendo novas hipóteses de inelegibilidade relativa; Lei n. 10.028/2000, que tratou sobre os crimes contra finanças públicas; Lei n. 12.846/2013 (Lei Anticorrupção), que dispõe sobre a responsabilização administrativa e civil de pessoas jurídicas pela prática de atos contra a administração pública, sendo a única, dentre as anteriores, que traz algumas medidas preventivas, como o compliance, que gerou muito entusiasmo, porém pouca implementação até o momento.

Além disso, as denominadas 10 medidas contra a corrupção, esboçadas pelo Ministério Público Federal como projeto de lei de iniciativa popular, que recebeu o endosso de mais de dois milhôes de cidadãos e atualmente tramita de forma conturbada perante a Câmara dos Deputados, sob as quais tem-se depositado todas as esperanças em dias melhores e instituições mais éticas, não expõem um panorama diferente do controle que chega atrasado.

O problema é que oferece visões parciais de uma situação complexa, tal como os cegos que, no conto hindu, são impelidos a descrever um elefante. $\mathrm{O}$ primeiro cego, apalpando a trompa do animal, afirmou se tratar de algo longo e elástico como uma mangueira; o segundo, tocando em uma de suas orelhas, disse que era plano e largo com uma folha de taioba; o terceiro tocou a barriga do elefante e assegurou ser alto e sólido como uma parede; o quarto, abraçado a perna do paquiderme, disse que era duro e redondo como um pilar. Quatro descriçôes que, embora corretas quanto à parte que tocavam, não conseguiram descrever o elefante como um todo. Semelhante impasse acomete as discussões sobre o controle da corrupção: visões parciais dificilmente alcançarão soluções integrais. ${ }^{106}$

106 BAUTISTA, Oscar Diego. Cómo abordar la corrupción? Una vía para su solución a través de la ética pública. Revista Direito UFMS. Campo Grande-MS, v. 2, n. 1, p. 25-38, 2016. 
A despeito de reticências pontuais que guardo em relação a algumas dessas medidas, só o tempo irá mostrar se serão eficazes ou não, ou se se arvorar-se-ão em abusos. O fato é que elas passam à sociedade a noção (equivocada) de que o combate à corrupção e aos desvios éticos depende exclusivamente do incremento de penas, do número crescente de crimes hediondos e do poder sancionatório dos órgãos de persecução. Não há como negar que tudo isso seja realmente importante do ponto de vista dissuasório. Entretanto, esse enfoque limitado provavelmente decepcionará aqueles que acreditam na promessa de que a corrupção termina onde começa a punição.

Não é assim. A superveniência de penas mais altas não é capaz, por si só, de ajustar os ponteiros éticos da sociedade. A repressão cível, criminal e administrativa não transforma a sociedade do jeitinho, o capitalismo do compadrio e o patrimonialismo, incrustrados em nossa sociedade desde há séculos, de modo que se deve dar igual atenção a outras formas de abordagem do controle.

Aliás, alguns especialistas afirmam que essa ênfase desproporcional nas penas, em detrimento do foco na prevenção e nos estímulos à integridade, tem feito reduzir a eficácia dos esforços anticorrupção. Para mais, a tendência à alta regulamentação legal, que costuma preencher vácuos deixados por grandes escândalos de corrupção, pode ser contraproducente. ${ }^{107}$

É preciso, portanto, erguer a cabeça das escaramuças cotidianas e olhar o problema através de outra lente, que nos permita enxergar mais longe, e com maior precisão. Ser capaz de visualizar a distância esses problemas nos dá mais formas de evitar que ele chegue até nós. É dizer: devemos refletir também - e principalmente - sobre o período pré-lesão; pré-corrupção, sobre a vocação preventiva do controle, baseada na construção de uma cultura de integridade.

Parece estar fugindo à memória brasileira a lição que nos é transmitida pelos pais ainda cedo: prevenir é melhor do que remediar. Ou devemos esperar que seja consumado o superfaturamento; o conluio; a propina; o desvio; a fraude; para depois atuar e correr atrás do prejuízo? Não seria melhor que, ao invés de permanecer perseguindo a corrupção, colocássemos uma pedra enorme chamada controle em seu sapato para que ela não consiga ir tão longe, nem tão rápido? A questão principal é definir as estratégias mais adequadas para antecipar a jogada desse adversário tão insistente.

107 KAUFMANN, Daniel. Myths and realities of governance and corruption. Natural Resource Governance Institute, p. 88. 
Ocorre que no debate, quase sempre pobre, sobre a corrupção e o desperdício de recursos públicos no Brasil, o culto à repressão deixa diversas questóes essenciais fora da agenda de debates, entre as quais: $\mathrm{O}$ Brasil possui uma estrutura permanente de prevenção com a finalidade de evitar desvios e desperdícios de dinheiro público? Deveríamos estar entregues à vontade de criminosos confessos e dependendo de golpes de sorte para desvendar episódios de fraude e má-gestão pública, ou seu enfrentamento se faz diariamente, através da construção de valores republicanos e de uma governança baseada na ética? Como fomentar a integridade? Que valor nós damos aos cidadãos que se levantam contra 2005, a corrupção e ajudam a inibi-la? O nosso controle formalístico, restrito à análise de conformidade das condutas à lei, é capaz de fomentar gestôes éticas e políticas eficientes, eficazes e econômicas? Há alguma preocupação com a estruturação e funcionamento dos controles internos nos poderes de todas as esferas de governo? Os Tribunais de Contas já consolidaram diretrizes que reforcem a atuação preventiva e concomitante de fiscalização da coisa pública?

Há um ponto comum nessas provocações: a percepção de que o caráter repressivo que espelha o nosso sistema de combate à corrupção é uma arma que estará sempre muitos passos atrás da atitude mais efetiva para resguardar as finanças públicas: a prevenção.

Um esclarecimento: não pretendo menosprezar os argumentos bastante válidos no sentido de que a punição, afinal, também representa uma forma mediata de prevenção, já que, dissuadindo o agente corrupto, evita que o mesmo reitere as condutas ilícitas que vinha praticando, seja pela implicação da restrição à sua liberdade, daí impedindo fisicamente a reincidência do ato corrupto, seja porque surtiu efeitos pedagógicos fortes o suficiente para conscientizá-lo, e torná-lo exemplo para os demais, de que o crime não compensa. $\mathrm{O}$ meu ponto é que esta perspectiva, ainda que verdadeira, é limitada.

No mais das vezes, a abordagem sobre as ações de combate à corrupção, inefetividade e desperdício omitem - intencionalmente, talvez - que travar essa luta exige esforços operacionais e financeiros, os quais poderiam ser utilizados em áreas sociais de maior prioridade, como segurança, saúde e educação, segmentos nos quais o Brasil não apresenta senão pioras significativas nos últimos anos. Pouco se fala acerca da relação custo-benefício do controle. Se levarmos em conta essas variáveis, é indiscutível que o controle preventivo é mais recomendável.

Uma vez perpetrado o dano, tentar amenizar os seus efeitos ou recompor o patrimônio subtraído, na maioria das hipóteses se mostra contraproducente. Mesmo no âmbito da Operação Lava-Jato, onde se estima uma recuperação de ativos 
dentre as maiores que o mundo já viu em casos de corrupção, em torno de $\mathrm{R} \$ 10$ bilhôes $^{108}$ (incluindo nesta conta a recomposição por meio de acordos de leniência com empresas envolvidas), certamente não se chegou, nem se chegará ao resgate total daquilo que fora retirado ilegalmente dos cofres públicos. As experiências pretéritas mostram que a recuperação de valores dificilmente é favorável. Por exemplo, as decisões dos Tribunais de Contas são testemunhas eloquentes desse histórico negativo, já que apresentam um índice de recomposição baixíssimo, entre 1 e $14 \%$, dentre as cortes estaduais, referente às multas e débitos aplicados em seus acórdãos condenatórios. Não obstante o caso das cortes de contas detenha problemas específicos sobre os quais já falamos anteriormente, o fato é que os instrumentos de recuperação ordinários, por terem de correr atrás daquilo que não está mais lá - o dinheiro público desviado - são invariavelmente lentos e custosos, tornando necessário o dispêndio crescente de recursos operacionais e financeiros à medida em que a corrupção aumenta, gastando para recuperar o prejuízo. No final das contas, se tudo correr bem e o dinheiro subtraído, desviado ou desperdiçado retornar aos cofres públicos, ainda é possível que a conta desse procedimento fique zerada em comparação com os recursos que foram utilizados no processo de recomposição.

Esse não é o único problema. Embora o prejuízo numérico verificado na prática desses ilícitos seja mais perceptível, o custo econômico não é o único, e nem o mais importante aspecto a ser analisado nesses casos, porque ainda que a responsabilização administrativa, cível ou penal seja consumada, possibilitando o retorno do dinheiro desviado, permanece sem reparo o dano provocado pela perda de oportunidade. ${ }^{109}$ Considerando que os recursos públicos são destinados à execução de políticas e serviços públicos úteis e necessários ao desenvolvimento da sociedade, o desvio na rota do dinheiro alocado para estas finalidades retira-lhe a oportunidade de usufruir do hospital público, da creche, da estrutura rodoviária. O tempo perdido, não se recupera, não volta atrás. Uma eventual recomposição posterior desse patrimônio surrupiado não será capaz de reestabelecer o benefício social que deixou de ser proporcionado.

Deste modo, o caráter preventivo do controle não é só mais eficaz na manutenção dos recursos, mas também confere efetividade ao benefício social que se pretende alcançar com esse dinheiro.

108 SCHMITT, Gustavo; CARVALHO, Cleide. Três anos de Lava-Jato. O Globo. Disponível em: <http://oglobo.globo.com/brasil/tres-anos-de-lava-jato-21043383>. Acesso em: 12 mar. 2017.

109 TCU. Referencial de combate à fraude e à corrupção. Aplicável a órgãos e entidades da Administração Pública, 2016, p. 10. 
Para que entremos de vez nesse ambiente preventivo, devemos compreender a corrupção e os desvios éticos através de suas causas - já que a maioria das proposições de combate procura mitigar os seus sintomas - e a partir daí, trabalhar para que sejam bloqueadas essas vias causais na medida do possível. Temos de lembrar também que a corrupção não tem origem necessariamente em falhas educacionais ou morais de indivíduos ou burocratas (embora sejam aspectos relevantíssimos), mas possui raízes institucionais e este debate também deve ser travado. Para tanto, é importante partir de uma premissa bastante verossímil: corrupção é produto de uma governança frágil e ineficiente. ${ }^{110}$

Não por acaso a via metodológica para aferição de alguns indicadores de corrupção utiliza como critério a governabilidade e as capacidades institucionais do país, as quais, embora não forneçam diretamente uma medida exata do nível de corrupção em determinado país, permitem conhecer os espaços de discricionariedade e fragilidade governamental, que criam os incentivos oportunos para o cometimento de desvios públicos. ${ }^{111}$

Essa premissa não é de modo algum despida de suporte empírico. Basta examinarmos os resultados da alocação de recursos no âmbito social (educação e saúde), o que revela claramente a existência de uma gestão inepta, isto é, governança fragilizada na aplicação do patrimônio do Estado, produto da corrupção e da irrealidade dos gastos que estão relacionados a tais políticas. É possível ainda refletir sobre como a governança pode determinar o sucesso (ou fracasso) das estratégias anticorrupção. Podemos ver como isso funciona se analisarmos, por exemplo, o processo de descentralização administrativa, que geralmente é visto como um bom modo de aproximar o controle social das autoridades públicas que, entretanto, em sociedades marcadas por uma governança frágil, como constatado nas Filipinas pelo Banco Mundial, nos anos 1990, ${ }^{112}$ podem multiplicar, ao invés de limitar, as oportunidades para a corrupção, ao criar novos centros de poder com autoridade sobre a alocação de recursos públicos. De igual modo, os grupos de vigilância cidadã (watchdog agencies, na língua de origem), somente tiveram êxito em países cujo

110 Banco Mundial. Governance: the Worlds Bank experience, 2007, p. 67.

111 Como o "Indice Agregado e Individual de Governança", aferido pelo Banco Mundial no programa "Governance Matters" e o "Indice de Integridade Global". Ademais, indicadores regionais como o "Índice Nacional de Corrupção e Bom Governo", utilizado no México, mede a corrupção através da percepção dos cidadãos sobre 35 serviços públicos oferecidos pelos três níveis de governo.

112 TAPALES, Proserpina. An evaluation of anti-corruption programs in Philippines. World Bank, Operations Evaluation Department, Washington, DC, 2001. 
nível de governança é consideravelmente bom, como Austrália, Chile e Hong Kong, não tendo o mesmo sucesso em cenários adversos, a exemplo da Nigéria. ${ }^{113}$

Alina Mungiu-Pippidi reforça este argumento, ao apresentar evidências concretas de que a existência de leis de acesso à informação somente apresenta efeitos positivos, em termos de controle da corrupção, se a sua implementação ocorre em sociedades com maior nível de abertura social (boa governança). ${ }^{114}$

Quando a corrupção atinge certo patamar em que é incentivada pela ineficiência do próprio sistema, o suborno e a propina tornam-se coisas banais e a ação do governo fica submetida a todo tipo de interesses privados. Surgem então eufemismos grotescos para rotular práticas corruptas que passam a integrar a rotina administrativa, como o "custo político" de 3\% no âmbito federal, 5 a 10\% nos estados e 10 a 30\% nos municípios, referente às propinas pagas para firmar contratos com o governo, no Brasil, constante do depoimento de um dos delatores da Operação Lava-Jato. ${ }^{115}$

A clássica definição normativa e individualista da corrupção, defendida nas escolas de direito, leva em conta uma conduta que desvia das obrigaçôes formais públicas, com o fim de obter ganhos privados, ou seja, uma exceção à regra de integridade. O que essa abordagem ignora, no entanto, é que em determinados contextos, os desvios não constituem exceção, senão a regra do sistema, operando como um verdadeiro modelo de alocação particularista, ligado ao favoritismo, ao clientelismo e à impunidade. Neste caso, evoluir para um contexto de integridade não é algo que conseguiremos apenas reprimindo pontualmente delitos ou buscando o ressarcimento das perdas.

Em um ambiente como este, as medidas convencionais de controle tornam-se insuficientes, pois é improvável que as estratégias anticorrupção tenham sucesso a não ser que compreendam o contexto institucional. O que pretendo dizer é: na medida em que a corrupção é sintoma de uma falha sistêmica de governança,

113 SHAH, Anwar. Tailoring the fight against corruption to country circumstances. In: World Bank, Performance accountability and combating corruption. Edited by Anwar Shah. Washington D.C, 2007, p. 233-254: "Somente focando na governança é provável que a luta contra a corrupção seja exitosa a longo prazo" (tradução nossa).

114 MUNGIU-PIPPIDI, Alina. The quest for good governance. How societies develop control of Corruption. Cambridge University Press, 2015.

115 AFFONSO, Julia; BRANDT, Ricardo; MACEDO, Fausto; COUTINHO, Mateus. Delator-bomba da Lava Jato diz que propinas nas eleiçōes vêm desde 1946. Estado de S.Paulo. Política. Disponível em: <http://politica.estadao.com.br/blogs/fausto-macedo/delator-bomba-da-lava-jato-diz-que-propinas-nas-eleicoes-vem-desde-1946/>. Acesso em: 10 fev. 2017. 
quanto maior for a sua incidência [da corrupção], menos a estratégia anticorrupção deve incluir táticas que mirem estritamente punir comportamentos corruptos isolados, e mais deve focar nas grandes características que são subjacentes ao ambiente governamental, como o fortalecimento da cultura de integridade, do estado de direito, e dos mecanismos de transparência, participação e prestação de contas (accountability). É uma questão de governança, atinente, por um lado, à configuração das regras do jogo sobre como os recursos são distribuídos e, por outro, à capacidade da sociedade de impor restriçōes (bloqueios) ao uso da autoridade pública com o fim de gerar rendas privadas, em detrimento do bem-comum.

Buscarei desenvolver melhor essa premissa em favor da prevenção partindo das perspectivas racionalistas do comportamento desonesto, que tomam a corrupção como resultado de um processo cognitivo complexo e não intuitivo, baseado em riscos e incentivos.

Começo pela teoria do criminologista norte-americano Donald Ray Cressey, denominada "triângulo das fraudes". ${ }^{116}$ Segundo essa teoria, para a ocorrência da fraude, deve haver a confluência de três fatores distintos: primeiro, a pressão, presente nos incentivos que o agente tem para levar a cabo o ato desonesto, a exemplo do montante elevado que poderá receber como resultado de sua prática; segundo, a oportunidade, que diz respeito à fraqueza do sistema de governança e de controle, diminuindo os riscos para o agente e tornando a fraude possível e, finalmente, a racionalizaçãa ${ }^{117}$ referente ao processo interno (na mente corrupta) de construir uma explicação moral razoável que procure justificar o ato ilegal como algo aceitável ou justo.

A ideia de racionalização faz referência àquilo que os teóricos costumam chamar de efeito ladeira escorregadia (slippery slope) ou bola de neve. Com maior expressão nos Estados Unidos, tal locução designa a conduta daquele que pratica uma infração de menor relevância e, por idealizar falsas justificativas morais, pensa que está agindo dentro da normalidade. Com isso, passa a sempre procurar motivações para condutas cada vez mais graves, sem, contudo, deixar de elaborar uma autoimagem positiva que incuta nele mesmo a percepção de que aquilo que faz é justificável.

116 CRESSEY, Donald R. Other people's money: a study in the social psychology of embezzlement. Montclair, NJ: Patterson Smith series in criminology, law enforcement \& social problems, 1973, p. 1-191.

117 MALEM SEÑA, Jorge F. Globalización, comercio internacional y corrupción. Gedisa, 2000: “(...) la corrupción como arma mercantil se convierte de ese modo en una cuestión de toma de decisión racional que es adoptada, planeada y ejecutada por empresarios con la complicidad de los funcionarios públicos". 
A corrupção, portanto, não é algo que acontece na sociedade como um desastre natural, de modo fortuito, mas como uma atuação racional de indivíduos e grupos que abusam da coisa pública em um dado ambiente de oportunidades, recursos e pressóes.

Esse balanceamento consciente entre incentivos e riscos é comum nos estudos sobre a corrupção. Robert Klitgaard ${ }^{118}$ o caracteriza como uma espécie de "equação básica da corrupção", determinada principalmente pelo alto nível de discricionariedade existente em torno das competências centralizadas de um funcionário público. Na prática, essa matemática que conduz à fraude é aplicada desde há muito. Os anões do orçamento, os mensaleiros, os dirigentes políticos, lobistas, operadores financeiros e empresários da Operação Lava-Jato certamente fizeram esse cálculo e tomaram a sua decisão.

A meu ver, merece uma atenção especial nesse desenho triangular o segundo ângulo: da oportunidade. $\mathrm{O}$ agente que possui diante de si uma governança manifestamente frágil, uma cultura debilitada, e um sistema de controle ineficiente na missão de inibi-lo, vê um caminho limpo para corromper e ser corrompido. Quanto maior for a percepção de que a corrupção é oportuna, política ou economicamente, tanto maior será a probabilidade de ela ocorrer. É um caminho sem volta: quando as oportunidades econômicas superam as políticas, os agentes inclinam-se a utilizar da riqueza para adquirir e corromper o poder; se, por outro lado, as oportunidades políticas excedem as econômicas, os agentes tendem a servir-se do poder para o enriquecimento pessoal. ${ }^{119}$ A questão central é como inverter essa estrutura maligna.

A experiência dolorosa que, espero, tenhamos acumulado ao longo dos últimos anos demonstra que não existe solução única ou desgarrada da governança capaz de solucionar esse problema por conta própria. O combate aos desvios éticos na administração não opera no estilo um-modelo-serve-para-todos (one-size-fits-all), mas se faz no dia-a-dia, em várias frentes e por todos os membros da sociedade. ${ }^{120}$ Uma gestão ética, aberta, dialética e eficiente da coisa pública, que consiga desempenhar as suas funçōes conforme um programa transparente e objetivo previamente estabelecido, somada a um controle efetivo, não deixa vácuos nos quais a corrupção e o desperdício possam proliferar.

118 KLITGAARD, Robert. Controlling corruption. Berkeley: University of California Press, 1998.

119 HUNTINGTON, Samuel P. Political order in changing societies. New Haven: Yale University Press, 1968, p. 59-71.

120 TCU. Referencial de combate à fraude e à corrupção. Aplicável a órgãos e entidades da Administração Pública. TCU, 2016, p. 10. 
Chegamos, portanto, a uma conclusão preliminar: o sucesso das políticas preventivas depende da boa governança. ${ }^{121}$ A sua falha, por outro lado, dificulta que às pessoas desfavorecidas obtenham serviços públicos de qualidade, bem como viabiliza aos agentes envolvidos aproveitarem da debilidade institucional para operar com impunidade.

Tal conclusão é compartilhada pelo Banco Mundial, conforme o Relatório Mundial de Desenvolvimento para o ano de 2017. Nele, o organismo internacional reforça que as abordagens tradicionais de controle da corrupção, a partir da criação de órgãos de combate aos delitos e promulgação de leis com sanções mais duras, apresentam resultados insatisfatórios em países nos quais os níveis de governança e os arranjos políticos são deficitários. ${ }^{122}$

É claro que um mundo cabe na definição aberta de "governança", mas o escopo deste trabalho precisa ser objetivo e certamente não pretendo deixar um vácuo na cabeça do leitor ao usar termos tão abrangentes, sem ao menos tentar sistematiza-los. É importante compreender esse conceito, pois ele servirá como base para todos os capítulos que se seguirão.

De forma simples, portanto, pode-se entender por governança as normas, instituições e processos pelos quais interagem os cidadãos, os representantes políticos e a administração pública, a fim de implementar e executar as políticas governamentais, visando relacionar os objetivos políticos, incluindo o processo pelo qual os governantes são escolhidos e monitorados. Em suma: é a capacidade do governo de implementar e formular políticas sólidas, que levem em consideração as necessidades e vontades da sociedade, apresentando os resultados obtidos para que sejam controlados por ela.

Essas normas, instituições e processos buscam sustentação em quatro princípios básicos: a) relações éticas (integridade) em todas as suas dimensões; b) transparência; c) participação (orientação pelo consenso e procedimentos de engajamento civil) e; d) prestação responsável de contas (accountability). ${ }^{123}$

Salvaguardar esses princípios é uma tarefa permanente, que exige comprometimento diário de todos os envolvidos. A propósito, não será a boa vontade dos

121 Banco Mundial. Relatório de Desenvolvimento Mundial. 2017, p. 1.

122 Também nesse sentido: "boa governança é um forte antídoto para a corrupção e fraude" (DYE, Kenneth M. Corruption and fraud detection by Supreme Audit Institutions. In: SHAH, Anwar. Performance accountability and combating corruption. The World Bank, 2007, p. 305).

123 IFAC Public Sector Committee. Governance in the public sector: a governing body perspective, 2001; United Nations Economic and Social Commission for Asia and the Pacific (UNESCAP): What is Good Governance?, 2010. 
agentes políticos que irá determinar a realização ou não dessa governança, tendo em vista o amplo reconhecimento da existência do direito fundamental à boa administração, quer dizer, à gestão eficiente, eficaz, efetiva, econômica, proporcional, transparente, moral e participativa da coisa pública (boa governança), onde vigore plenamente e a todo vapor a noção de responsividade (tornando convergentes os serviços públicos às preferências da sociedade) e responsabilidade (através da eficiência e equidade na provisão de serviços). Como qualquer outro direito fundamental, explícito ou implícito na Constituição Federal, a boa administração abrange outros direitos, como aqueles que protegem e inibem a apropriação privada do patrimônio econômico do Estado. ${ }^{124}$

Enquanto o governo não for capaz de transmitir que preza pelos interesses da sociedade, desde o ponto inicial até o fim do ciclo de gestão da coisa pública, não haverá norma, instituição, tampouco sanção, suficiente para transformar a percepção negativa sobre os níveis de corrupção brasileiros.

Há, no entanto, uma série de obstáculos que o Brasil precisa vencer antes de conseguir preencher todos os adjetivos que foram utilizados para qualificar a boa governança, e que servem igualmente ao controle. Dois desafios sobressaem: primeiro, superar o estigma que pesa sobre a administração pública, de só aparecer quando não funciona, ou quando funciona deficientemente, dando chances à dilapidação. Se o ônibus escolar transita regularmente, ninguém irá se lembrar que há uma estrutura administrativa funcionando para que isso aconteça. Mas a reação certamente é distinta se o mesmo ônibus estiver parado, ou superlotado. É preciso valorizar a boa gestão, a governança adequada, que cumpre os seus objetivos, separando o joio do trigo. Segundo, ultrapassar a noção anacrônica de que o controle é um instrumento de punição daquele que simplesmente não adaptou o seu comportamento à norma preestabelecida. Lógico que essa fase de adequação formal deve ser incluída na atividade de controle, como já dissemos, mas o seu aspecto principal é outro, o educativo, imunológico, que avalia as políticas públicas numa perspectiva de resultados e riscos, corrigindo a tempo e a contento os eventuais desvios na administração do dinheiro público.

Uma vez superados esses desafios atávicos, a boa governança e o controle preventivo se interligam para fechar as linhas de um ciclo virtuoso que busca o constante melhoramento na utilização do patrimônio do Estado, fechando cerco aos espaços [oportunidades] onde é possível que se cometam atos desonestos.

124 FREITAS, Juarez. Discricionariedade administrativa e direito fundamental à boa administração, 2009, p. 36. 
O que pretendo expor deste ponto em diante é precisamente o conjunto de medidas que, sem carregar o conteúdo negativo (reprovativo) de combate e repressão, próprio do controle tardio, enfoca no fortalecimento e desenvolvimento da prevenção. Numa ótica diferente, ao invés de medidas de combate, serão medidas a favor do controle. Esta é a lógica que orientará os próximos capítulos.

Antes, contudo, de apresentar esse rol de estratégias preventivas, convém ressaltar alguns outros pressupostos teóricos.

Primeiro, a corrupção no setor público, como sintoma de fragilidade no sistema de governança que instiga condutas oportunistas, é determinada por uma série de fatores conjunturais, como a ética e a integridade na administração, a relação de responsabilidade dos governantes com os governados, os procedimentos de participação da sociedade civil e o nível de transparência dos negócios públicos. A existência e reiteração de desvios na organização revelam que tais fatores não estão funcionando adequadamente, de modo que qualquer esforço direcionado ao controle da corrupção que não considere essas condições, muito provavelmente será falho e improdutivo. Neles, portanto, iremos nos concentrar.

Segundo, as medidas se basearão nos aspectos: ética, integridade, transparência, participação e accountability, como elementos que dão essência à noção de governo aberto. Assim, será empreendida uma análise específica de como estas condições influenciarão no desenvolvimento do controle preventivo.

Ciente de que não há respostas óbvias, tampouco receitas milagrosas para os problemas que foram anteriormente apontados, e de que transformaçôes institucionais têm a dimensão incontornável da reforma de um navio em meio à viagem, buscarei contribuir, o mínimo que seja, para a formulação de estratégias adequadas ao desenvolvimento de um programa sério de controle preventivo no Brasil. Para tanto, apresentarei mecanismos, instrumentos, proposiçôes e ideias que potencializem esses fatores, não só combatendo a corrupção, mas fomentando as práticas e condutas que desativem os elementos institucionais e culturais nos quais ela opera.

De partida, buscando facilitar a compreensão e o modo de implementação das propostas que serão descritas, decidi estabelecer um corte metodológico das medidas em dois grupos gerais. O primeiro diz respeito ao campo da ética e da integridade, abordando aspectos gerais sobre o comportamento dos agentes públicos e privados, de modo a promover ideias que revertam a vulgaridade moral que dá tom à nossa época, a partir da construção de um ambiente de decência pública. Convém lembrar que, segundo as teorias da cognição social, ${ }^{125}$ a conduta moral dos

125 MOSCOVICI, S. Why a Theory of social representation? In: DEAUX, K; PHILOGÈNE, G. (Ed.). Representations of the social. Oxford: Blackwell, 2001. 
indivíduos é produto mediato da influência social, ou seja, do número de outras pessoas engajadas em ações similares. A prevalecer uma cultura que não valoriza a honestidade, são grandes as chances de perpetuação de um ciclo vicioso que alimenta a corrupção. $\mathrm{O}$ segundo grupo tem aspecto estrutural, elencando medidas concretas e específicas de controle preventivo institucional, orientadas pelos vetores da transparência, participação e accountability, enquanto alicerces da noção atual de governo aberto.

Verifica-se que a maioria dos países desenvolvidos, e que ocupam boas posições nos índices de percepção de corrupção e governança, ou seja, que são menos corruptos, desenvolveram estratégias sustentáveis de prevenção alicerçadas justamente no estímulo à ética, políticas de integridade, abertura cívica e prestação de contas.

De que forma esses elementos poderiam influir na efetividade da prevenção? Tentarei responder de forma lógica e sequencial: por meio de um ambiente ético e íntegro, reduz-se a disposição para desvios de conduta ou desonestidades funcionais, restabelecendo a confiança da sociedade e aumentando o nível de censura interna e externa às irregularidades, o que tende a desenvolver uma cultura ativa de denúncia (whistleblower) e de conformidade (compliance) às leis do Estado de Direito. Além disso, através de medidas que incrementem a participação e a transparência, limita-se o risco de que as vulnerabilidades do sistema sejam exploradas como oportunidades por agentes mal-intencionados, na medida em que os atos da gestão pública passem a ser mais observados, monitorados e influenciados pelo interesse coletivo.

Para não correr o risco de colocar-se na estrada das expectativas destinadas à desilusão, tampouco fazer parecer que as medidas descritas não passam de apelos intuitivos ou recursos retóricos inúteis, tentarei ao máximo conferir uma fundamentação crível às escolhas, levando sempre em consideração as circunstâncias brasileiras (espaço, tempo, cultura e causalidades específicas), haja vista a necessidade de dar o passo conforme o tamanho das pernas.

Finalizando esse capítulo introdutório, registro a confiança e a esperança de que, se adotarmos o caminho do controle, o futuro nos reservará dias melhores. Devemos todos confiar no controle, pois se ele não servisse para melhorar a condição da sociedade, seria pura expressão de um poder vazio. Não interessaria a mim, nem a ninguém. $\mathrm{O}$ que deve nos mover à vida de fiscalização pública, não obstante as desilusões, os cansaços cotidianos, é a certeza de que o controle não é apenas uma ação de domínio fútil, mas serve também à justiça, para combater a prepotência do impune e a mortificar o ímpeto da corrupção. 
